\title{
Bubbling behavior in a waste glass melter
}

\author{
D. P. Guillen \\ Idaho National Laboratory, USA
}

\begin{abstract}
Legacy tank waste from five decades of plutonium production at the Hanford Site during the Cold War will be vitrified into a stable waste form for disposal. A Waste Treatment Plant, currently under construction, houses Joule-heated ceramic-lined waste glass melters wherein radioactive waste will be combined with glass formers to produce borosilicate glass. Through testing conducted in pilot-scale melters with surrogate waste, as well as operational experience at other sites, it has been demonstrated that the use of bubblers can dramatically improve the glass production rate. In this paper, parameters influencing the formation and rise of a bubble stream in a viscous liquid are investigated. Experimental data and observations from laboratory and pilot-scale testing are integrated with first principles to develop a set of equations that form a mechanistic bubbling model to be incorporated into the melter model.
\end{abstract}

Keywords: bubbling behavior, waste glass melter, vitrification.

\section{Introduction}

Joule-heated ceramic-lined waste glass melters are being installed at the Hanford Waste Treatment Plant for the vitrification of legacy radioactive tank waste. Radioactive waste will be combined with glass formers to produce a stable waste form for disposal. The waste slurry is charged to the melter from above. In each melter, electric current passes between immersed electrodes on opposite sides of the tank. The electrical resistance of the glass causes the electric current to be dissipated as heat, which supplies energy for the feed-to-glass conversion reactions that occur in the cold cap, a layer of reacting feed floating on top of the heated glass [1]. Above the glass is a plenum region which provides a space for the reaction gases and bubbles to vent before being funneled to the off-gas system.

Bubblers have been incorporated into the waste glass melters to improve the overall heat transfer and increase the glass production rate. The use of gas bubblers 
has been shown to increase the glass production rate in an operational melter by up to $66 \%$ [2]. Increased melting rates result from improved heat transfer from the glass pool to the cold cap. The addition of bubbling increases glass circulation within the melt pool and provides agitation to the melt surface to break up insulating foam layers in the cold cap. Heat from the hot fluid is continually supplied to the cold cap/glass interface, where it is used to drive the cold cap reactions [3]. Bubbling also increases heat transfer to the plenum, which provides heat to the cold cap from above.

However, knowledge of the bubble characteristics in the molten glass is necessary for accurate modeling of the melter. A computational fluid dynamics model of the melter has been developed to investigate the processes affecting melt rate [4]. Prior modeling studies have shown that the thermal convection currents within the melt pool due to Joule heating supplied by the electrodes are substantially altered by forced air bubbling [5]. In this paper, parameters influencing the formation and rise of a bubble stream in a viscous liquid are investigated. A set of equations are outlined that form a mechanistic model for bubbling to be incorporated into the melter model. When completed, the melter model will be used as a tool to assist in the prediction and design of improved melting processes.

\section{Melter description}

To gain a better understanding of the bubble behavior in the melter, an experimental campaign has been conducted at the Vitreous State Laboratory at the Catholic University of America [6]. Tests were performed in the DM1200 HighLevel Waste (HLW) Pilot Melter with molten glass. Unfortunately, the metal walls, cold cap layer, opaque fluid and high temperatures make it extremely difficult to obtain details on the bubbles within the glass. Therefore, a set of experiments were carried out in an acrylic tank where bubbling behavior with a glass simulant at room temperature could be visually observed. Additionally, videos taken during melter operations at the Defense Waste Processing Facility at the Savannah River Site were studied to provide an understanding of the physical behavior of the cold cap/melt pool surface during bubbling. This paper uses the experimental data and observations in concert with the physical laws of fluid dynamics to develop a mechanistic model that accurately describes the bubbling.

The acrylic tank used for the visual observations had a square cross-section that measured $0.762 \mathrm{~m} \times 0.762 \mathrm{~m}$ and was filled to a depth of $1.067 \mathrm{~m}$. The plenum region extended $0.61 \mathrm{~m}$ above the fluid surface to allow room for splashing. The fluid used in the tank experiments was a mixture of corn syrup and $\mathrm{ZnBr}_{2}$ (NOAH Technologies Corporation, San Antonio, Texas, USA) [6]. The advantages of using this fluid are its relative transparency and the fact that it doesn't solidify at room temperature. Digital video cameras recorded the bubbling tests.

A comparison of the physical properties of the molten glass and the corn syrup mixture is given in Table 1. Note that the specific gravity values of the molten glass and the corn syrup mixture are 2.4 and 2.0, respectively. This results in a hydrostatic pressure at the bubbler nozzle that is 2.0 to 2.4 times that of water. The 
viscosity of the corn syrup mixture is $67 \%$ higher than that of the glass, but nearly four orders of magnitude more viscous than water. The surface tension of the molten glass is slightly more than a factor of three higher than that of the corn syrup mixture and 4.5 times that of water at room temperature.

Table 1: $\quad$ Physical properties for molten glass and the corn syrup/ $/ \mathrm{ZnBr}_{2}$ mixture [6-9].

\begin{tabular}{|l|c|c|}
\hline Property & $\begin{array}{c}\text { Molten glass } \\
(@ 1423 \mathrm{~K})\end{array}$ & $\begin{array}{c}\text { Corn syrup/ } / \mathrm{ZnBr}_{2} \text { mixture } \\
(@ 293 \mathrm{~K})\end{array}$ \\
\hline Density, $\rho\left(\mathrm{kg} / \mathrm{m}^{3}\right)$ & 2,400 & 2,000 \\
\hline Viscosity, $\mu(\mathrm{Pa}-\mathrm{s})$ & 5.1 & 8.5 \\
\hline Surface tension, $\sigma(\mathrm{mN} / \mathrm{m})$ & 328 & 100 \\
\hline
\end{tabular}

\section{Experimental observations}

An illustration of the bubbler configuration in the acrylic tank is shown in Figure 1. A J-shaped bubbler tube with two orifices injects air at a constant flow rate into the fluid. The bubbles grow, then detach from the orifice and rise vertically to the surface. The bubbles were observed to be released from the injector at a frequency, $\mathrm{f}$, between 2.5 and 3 bubbles per second. It is interesting to note that the bubble frequency was not affected by a change in the gas flow rate, but the bubble size increased with increasing gas flow rate.

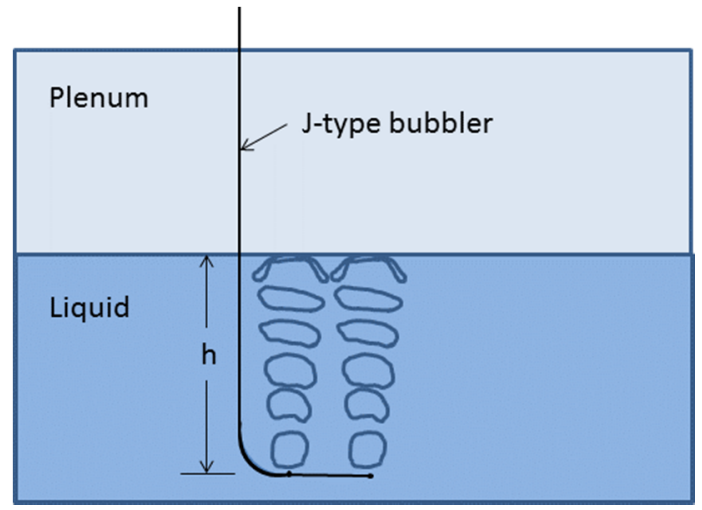

Figure 1: J-type double nozzle bubbler configuration.

In the experiments conducted with the corn syrup mixture at room temperature, the injected bubbles were photographed as they rose to the surface. As depicted in Figure 1, the bubble shape changes significantly as the bubbles rise towards the free surface. The first bubble in the sequence has a hemispherical upper surface and a bottom surface that is beginning to flatten. The next image in the sequence shows the base of the bubble slightly inverted. The base of the spherical-cap bubble then flattens in the subsequent image. During the ascent, the aspect ratio 
increases and the shape becomes ellipsoidal. The bubbles further elongate until the shape ultimately appears mushroom-like. When the bubble reaches the surface, it appears as a thin inverted cup with a final diameter that is roughly double that of the initial diameter. The large expansion of the bubble diameter occurs very close to the surface. Bubble coalescence may occur while the bubbles are rising under the force of buoyancy, depending upon the timing of the bubble release. In the tank experiments, coalescence was seen to induce a lateral component to the surface flow, resulting in large amount of sloshing. In the melter, this surface agitation could improve the heat transfer to the cold cap and consequently increase melt rate.

The evolution of bubble morphology can be aptly described by the following physical mechanism. As a large bubble rises in a viscous fluid under the action of buoyancy forces, the pressure gradient at the lower surface of the bubble becomes higher than that at the top surface. Substantial deformation is induced by the higher pressures on the front and rear surfaces, in contrast to the lower pressure along the sides of the bubble [10]. A jet of water pushes the bubble from below [11], causing the bubble to deform into a shell-like form.

The diameter of the bubbles impacting the surface of the corn syrup mixture could be clearly seen in the tank experiments. Two distinct circulation cells on the surface of the melt from a double nozzle bubbler can be seen in the photograph in Figure 2. Measurements of bubble diameters appearing in the circulation patterns on the glass surface ranged from $0.265 \mathrm{~m}$ to $0.321 \mathrm{~m}$. The projected areas of the bubbles after release from the orifices were also measured and found to increase with flow rate.

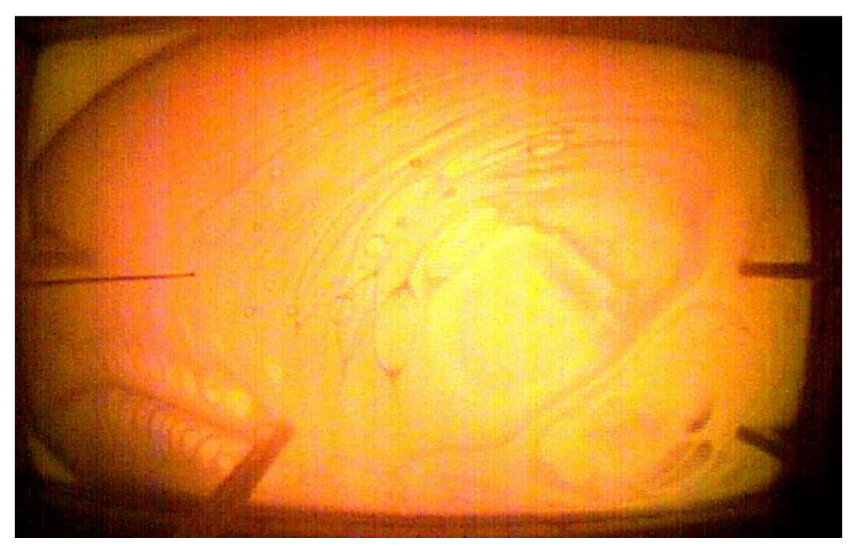

Figure 2: Photograph of circulation pattern on melt surface from a double nozzle bubbler [6].

The experimental data lead to the conclusion that larger bubbles are better than smaller bubbles at augmenting melting rate. The rising bubbles impart a shear force to the liquid glass, which results in forced convection with velocities more than an order of magnitude larger than those resulting from natural convection currents alone. Larger bubbles pump more glass, improving mixing and 
temperature uniformity, as well as yield a larger contact area with the cold cap. Videos taken during melter operation show vent holes in the cold cap located directly above the bubblers. Molten glass erupts through these vent holes. The photographs show liquid spewing violently from the liquid surface accompanied by sloshing and splashing. Larger bubbles induce large amplitude long wavelength sloshing on the melt surface, which promotes contact of the molten glass with the cold cap.

\section{Mechanistic model formulation}

\subsection{Physical laws}

The bubbling rates indicated by the mass flow controller are for gas flow under standard temperature and pressure conditions. Standard conditions are typically defined as pressure equal to $101.325 \mathrm{kPa}$, temperature equal to $293.15 \mathrm{~K}$ and $0 \%$ relative humidity. As the air flows through the bubbler tube that extends through the hot plenum and then is submerged in the hot molten glass, the air temperature within the bubbler increases. Due to the long lengths of bubbler tubing, the temperature of the air at the bubbler exit is estimated to be $903 \mathrm{~K}$ [12]. This causes the actual volumetric flow rate at the orifice to be different from that indicated by the mass flow controller. Note that the mass flow rate doesn't change, but the density and velocity do. Based upon conservation of mass, the mass flow rate at the exit of the bubbler tube, $\dot{m}_{\mathrm{e}}$, is equal to the mass flow rate under standard conditions at the inlet, $\dot{m}_{\text {std }}$

$$
\dot{m}_{\mathrm{e}}=\dot{m}_{\mathrm{std}}
$$

Therefore, by the definition of mass flow rate

$$
(\varrho Q)_{e}=(\varrho Q)_{s t d}
$$

and

$$
Q_{e}=Q_{s t d} \frac{\rho_{s t d}}{\rho_{e}}
$$

The air density at the bubbler exit can be calculated from the ideal gas law

$$
\varrho_{e}=\varrho_{s t d} \frac{P_{e}}{P_{s t d}} \frac{T_{s t d}}{T_{e}}
$$

which results in the following relationship for flow rate

$$
Q_{e}=Q_{s t d} \frac{P_{s t d}}{P_{e}} \frac{T_{e}}{T_{s t d}}
$$

where

$\mathrm{Q}_{\mathrm{e}}=$ Bubbler exit flowrate, $1 / \mathrm{min}$,

$\mathrm{Q}_{\text {std }}=$ Flowrate measured by mass flow controller, $1 / \mathrm{min}$,

$\rho_{\mathrm{e}}=$ Air density at bubbler exit, $\mathrm{kg} / \mathrm{m}^{3}$,

$\rho_{\text {std }}=$ Air density at standard conditions, $\mathrm{kg} / \mathrm{m}^{3}$,

$\mathrm{P}_{\mathrm{e}}=$ Bubbler exit pressure, $\mathrm{Pa}$,

$\mathrm{T}_{\mathrm{e}}=$ Bubbler exit air temperature, $\mathrm{K}$,

$\mathrm{T}_{\text {std }}=$ Standard temperature, $\mathrm{K}$,

$\mathrm{P}_{\text {std }}=$ Standard air pressure, $\mathrm{Pa}$. 
The pressure at the nozzle outlet, $\mathrm{P}_{\mathrm{a}}$, is equal to the melter pressure, $\mathrm{P}_{\text {melter, }}$ plus the hydrostatic pressure of the molten glass

$$
P_{e}=P_{\text {melter }}+\varrho_{l} g h
$$

where

$\mathrm{h}=$ nozzle depth (measured from melt pool surface), $\mathrm{m}$.

It is assumed that the pressure drop in the line is negligible and there is no moisture ingress into the air. The melter is typically operated under a slight vacuum of -25 to $-50 \mathrm{~Pa}$ [13]. Assuming an average value for the vacuum pressure in the melter, Equation (4) applied to a rising bubble becomes

$$
\varrho_{\text {bubble }}=\left(c_{1}+c_{2} h\right) T_{\text {bubble }}^{-1}
$$

where

$\mathrm{c}_{1}=345.027 \mathrm{~kg}-\mathrm{K} / \mathrm{m}^{3}$,

$\mathrm{c}_{2}=80.151 \mathrm{~kg}-\mathrm{K} / \mathrm{m}^{4}$.

Equation (7) can be implemented into the melter model to prescribe the change in the density of the air within the bubble, Pbubble, as a function of the air temperature inside of the bubble, $\mathrm{T}_{\text {bubble, }}$ and bubbler nozzle depth. The bubbles will expand as they ascend due to the combined effects of heating of the bubble by the surrounding hot glass and the reduction in hydrostatic pressure. If density is assumed to vary with temperature only (and $\mathrm{h}$ is held constant at $0.689 \mathrm{~m}$ ), the polynomial equation becomes

$$
\varrho_{\text {bubble }}=c_{3} T_{\text {bubble }}^{-1}
$$

where

$\mathrm{c}_{3}=399.995 \mathrm{~kg}-\mathrm{K} / \mathrm{m}^{3}$.

\subsection{Non-dimensional bubble parameters}

The motion of a gas bubble steadily rising in a liquid can be characterized by the following seven independent dimensional quantities: the liquid and gas densities, $\rho_{1}$ and $\rho_{\mathrm{g}}$; the liquid and gas viscosities, $\mu_{1}$ and $\mu_{\mathrm{g}}$; the gravitational acceleration, $\mathrm{g}$; the coefficient of surface tension, $\sigma$; and bubble diameter, D. According to the Buckingham Pi theorem of dimensional analysis, the following five independent non-dimensional parameters can be formed to describe the problem [14]

$$
\begin{gathered}
\gamma=\frac{\rho_{g}}{\rho_{l}} \\
\kappa=\frac{\mu_{g}}{\mu_{l}} \\
E o=\frac{g D^{2} \Delta \varrho}{\sigma} \cong \frac{g D^{2} \varrho_{l}}{\sigma} \\
M=\frac{g \Delta \varrho \mu_{l}^{4}}{\varrho_{l}^{2} \sigma^{3}} \cong \frac{g \mu_{l}^{4}}{\varrho_{l} \sigma^{3}} \\
R e=\frac{\varrho_{l} D U_{T}}{\mu_{l}}
\end{gathered}
$$

The density ratio, $\gamma$, affects the bubble buoyancy. The density difference between dispersed (bubble) and continuous (liquid) phases, $\Delta \rho$, is approximately equal to the liquid density since $\rho_{1} \gg \rho_{g}$. The viscosity ratio, $\kappa$, does not have a 
significant effect on the motion or shape of the rising bubble [11]. The Eötvös number, Eo, represents the ratio of buoyancy to surface tension [15]. The Morton number, M, is constant for a given fluid [15]. The Reynolds number, Re, represents the ratio of inertia to viscous forces. The terminal velocity of the bubble, $U_{T}$, is needed to calculate Reynolds number. Terminal velocity is defined as the steady velocity that the bubble attains due to the balance between buoyancy and drag forces [10]. Collins [16] modified the Davies and Taylor [17] relation for the terminal velocity, $\mathrm{U}_{\mathrm{T}}$, of a large spherical-cap gas bubble as

$$
U_{T}=0.652 \sqrt{\frac{g a \Delta \rho}{\rho_{l}}} \cong 0.652 \sqrt{g a}
$$

where

$\mathrm{a}=$ radius of curvature of spherical-cap bubble, $\mathrm{m}$.

An interesting characteristic of the bubble flow dynamics is that the steadystate rise velocity is independent of the fluid properties. Therefore, the bubble terminal velocity should be approximately the same in both fluids (molten glass and corn syrup mixture) for the same size bubble. From examination of the experimental data, it is seen that: (1) the bubble diameter roughly doubles from the time it departs the nozzle to the time it impacts the melt surface, and (2) the shape changes from initially spherical to spherical-cap with the bubble flattening as it rises. Observations from various investigators found that the radius of curvature of the spherical-cap bubble is 2.4 times that of the initial bubble diameter [18]. The bubble terminal velocity calculated from the above equations will be compared to that computed in the computational fluid dynamics simulation. [6]

The bubble departure diameter, $\mathrm{D}$, can be estimated by the following equation

$$
D=\sqrt[3]{\frac{12}{\pi} \frac{Q_{e}}{f}}
$$

It is assumed that the bubbles are initially spherical. Equation (15) accounts for the splitting of the gas flow by the double nozzle bubbler. For a standard flow rate of $65 \mathrm{l} / \mathrm{min}$, the actual flow rate at the bubbler exit is approximately $175 \mathrm{l} / \mathrm{min}$. Using an average bubble departure frequency, $\mathrm{f}$, of $2.75 \mathrm{~s}^{-1}$ from the experiments, a bubble departure diameter of $0.159 \mathrm{~m}$ is calculated.

Table 2 lists the calculated non-dimensional parameters for the molten glass and corn syrup mixtures. These parameters were calculated based upon the initial bubble diameter stated above. Observations from the experiments are in agreement with the shape regime map shown in Figure 3 correlating bubble shape with the Eötvös, Morton and Reynolds numbers. It is interesting to note, that in the nondimensional parameters given by Eötvös, Morton and Reynolds numbers, the density and viscosity of the fluid within the bubble are not included.

Bubbles are typically categorized according to their final shape [10]. From Equations (11-14), the dependence of Morton number on Eötvös and Reynolds numbers is evident. Therefore, only two parameters - either the Eötvös and Morton numbers or the Eötvös and Reynolds number - are necessary to specify the regime [14]. The combination of low Reynolds number, high Eötvös and high 
Table 2: Comparison of non-dimensional parameters for molten glass and the corn syrup $/ \mathrm{ZnBr}_{2}$ mixture.

\begin{tabular}{|l|c|c|}
\hline Non-dimensional parameter & $\begin{array}{c}\text { Molten glass } \\
(@ 1423 \mathrm{~K})\end{array}$ & $\begin{array}{c}\text { Corn syrup/ } \mathrm{ZnBr}_{2} \text { mixture } \\
(@ 293 \mathrm{~K})\end{array}$ \\
\hline Reynolds number, Re & 94 & 47 \\
\hline Morton number, $\mathrm{M}$ & 78 & 25,596 \\
\hline Eötvös number, Eo & 1,814 & 4,958 \\
\hline Density ratio, $\gamma$ & $4.906 \times 10^{-4}$ & $5.887 \times 10^{-4}$ \\
\hline Viscosity ratio, $\kappa$ & $3.62 \times 10^{-6}$ & $2.172 \times 10^{-6}$ \\
\hline
\end{tabular}

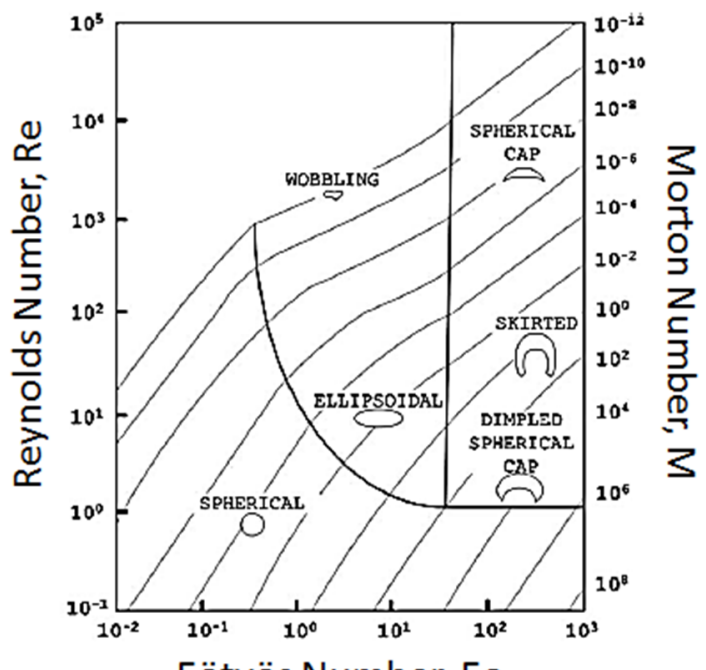

Eötvös Number, Eo

Figure 3: $\quad$ Shape regime map for bubbles rising through liquids [19].

Morton numbers place the bubbles in the skirted spherical cap regime for the molten glass and in the dimpled to skirted spherical cap regime for the corn syrup mixture.

\subsection{Drag and heat transfer coefficient}

The bubble drag coefficient is given by Clift et al. [19] as the generalized form of an equation originally suggested by Darton and Harrison [20] applicable to spherical-cap bubbles for Morton number $>10^{2}$ and all Reynolds numbers

$$
C_{D}=\frac{8}{R e} \frac{(2+3 \kappa)}{(1+\kappa)}+\frac{8}{3}
$$

Heat transfer to the bubbles from the molten glass is prescribed using the following formula for Nusselt number, $\mathrm{Nu}$ [18]

$$
N u=2.113(P e)^{0.5}
$$


This formula was derived analytically and accounts for convective heat transfer from all surfaces of the spherical-cap bubble. In Equation (17), Pe is the Peclet number given by

$$
P e=\frac{U_{T}(2 a)}{\alpha}
$$

where

$\alpha=$ thermal diffusivity of the molten glass, $\mathrm{m}^{2} / \mathrm{s}$.

The heat transfer coefficient for the bubble, $\mathrm{h}_{\mathrm{bub}}$, is obtained from the Nusselt number by

$$
h_{b u b}=\frac{k N u}{D}
$$

where

$\mathrm{k}=$ thermal conductivity of the molten glass, $\mathrm{W} / \mathrm{m}-\mathrm{K}$.

\section{Model implementation}

A three-dimensional computational fluid dynamics model is being developed to study the heat transfer and fluid dynamics occurring in the melter. The goal is to construct a high-fidelity multiphase simulation of the melter that allows the user to explore the effects of varying operational parameters on melter performance. The Reynolds Averaged Navier Stokes equations are solved for the fluid flow. Ohmic heating from the immersed electrodes and heat transfer to the cold cap are included. The complex cold cap processes (i.e. heat transfer, mass transfer and reaction kinetics) are described by a high-fidelity mathematical model (developed by Pokorny and Hrma [21]) coupled to the melter model.

A set of equations describing the physics of the bubbles injected into the waste glass melter have been outlined in Section 4. These equations form a mechanistic model that will be incorporated into the melter model. It is essential to provide an accurate description of the bubbling since the bubbles significantly enhance the liquid convection currents and promote mixing, which in turn affects the feed-toglass reactions in the cold cap.

\section{Summary}

In this paper, a set of equations are formulated to describe the bubbling behavior in a waste glass melter. A mechanistic model has been developed that can be readily implemented into the computational fluid dynamics model of the waste glass melter. The formulation is based upon experimental data and observations from pilot scale testing and experiments with bubbles injected into viscous fluids, empirical correlations obtained from the published literature, and the basic laws of fluid dynamics. The key parameters that influence bubble behavior are the fluid properties and the bubbler conditions (flow rate, bubble release frequency and depth). Computational fluid dynamic simulations will be conducted for the waste glass melter equipped with bubbling to investigate the coupled physicochemical processes occurring within the melter that affect performance, glass production rate and waste form durability. 


\section{Acknowledgements}

This manuscript was authored by Battelle Energy Alliance, LLC under DOE Contract No. DE-AC07-05-ID14517. Funding was provided by the DOE Office of River Protection, Waste Treatment and Immobilization Plant Project under the direction of Albert A. Kruger.

\section{References}

[1] Hrma, P., Conversion of Nuclear Waste into Nuclear Waste Glass: Experimental Investigation and Mathematical Modeling, 2nd International Summer School on Nuclear Glass Wasteform: Structure, Properties and Long-Term Behavior, SumGLASS 2013, Procedia Materials Science, 7, pp. 117-123, 2014.

[2] Hodges, B.C., Iverson, D.C. and Diener, G., Operation of Bubblers in the Savannah River Site Defense Waste Processing Facility Melter, Paper 12166, Waste Management WM2012 Conference, Phoenix, AZ, USA, February 26-March 1, 2012.

[3] Pokorny, R., Kruger, A.A. and Hrma, P., Mathematical Modeling of Cold Cap: Effect of Bubbling on Melting Rate, Ceramics-Silikaty, 58(4), pp. 296302, 2014.

[4] Guillen, D.P. and Beers, C.J., Modeling the Vitrification of Hanford Tank Waste, Transactions of the American Nuclear Society, 112, June 2015.

[5] Chapman, C., Modeling the HLW Melter with Revised Bubbler Design and Noble Metals, REP-PLT-069, Rev. 0, Duratek, Inc., Richland, Washington, September 26, 2005.

[6] Mohr, R.K., Chapman, C.C. and Pegg, I.L., High-Level Waste Melter Alternate Configuration Testing, The Catholic University of America, Vitreous State Laboratory, VSL-04R4800-3, Rev. 0, June 18, 2004.

[7] Hrma, P., High Temperature Viscosity of Commercial Glasses, CeramicsSilikaty, 50(2), pp. 57-66, 2006.

[8] Gan, H. et al., Crystal Settling, Redox, and Properties of ORP HLW \& LAW Glasses Final Report, The Catholic University of America, Vitreous State Laboratory, VSL-09R1510-1, Rev. 0, pp. T-21, March 31, 2009.

[9] Scholze, H., Glass Nature, Structure and Properties, Springer-Verlag, New York, NY, 1991.

[10] Amaya-Bower, L. and Lee, T., Single Bubble Rising Dynamics for Moderate Reynolds Number using Lattice Boltzmann Method, Computers and Fluids, 39, pp. 1191-1207, 2010.

[11] Chen, L., S. Garimella, S.V., Reizes, J.A. and Leonardi, E., The Development of a Bubble Rising in a Viscous Liquid, J. Fluid Mech., 387, pp. 61-96, 1999.

[12] Chapman, C.C. and Lutze, W., Computer Simulation Study of the Behavior of Noble Metals in the WTP HLW Melter, The Catholic University of America, Vitreous State Laboratory, VSL-05R5740-2, Rev. 0, August 8, 2005. 
[13] Matlack, K.S., Diener, G., Bardakci, T. and Pegg, I.L., Summary of DM1200 Operation at VSL Final Report, The Catholic University of America, Vitreous State Laboratory, VSL-06R6710-2, Rev. 0, September 7, 2006.

[14] Smolianski, A., Haario, H. and Luukka, P., Numerical Study of Dynamics of Single Bubbles and Bubble Swarms, Applied Mathematical Modeling, 32(5), pp. 641-659, May 2008.

[15] Esmaeeli, A. and Tryggvason, G., Direct Numerical Simulations of Bubbly Flows. Part 1. Low Reynolds Number Arrays, J. Fluid Mech., 377, pp. 313345, 1998.

[16] Collins, R., A Second Approximation for the Velocity of a Large Gas Bubble Rising in an Infinite Liquid, J. Fluid Mech., 25, pp. 469-480, 1966.

[17] Davies, R.M. and Taylor, G., The Mechanics of Large Bubbles Rising through Extended Liquids and through Liquids in Tubes, Proc. R. Soc. Lond., Ser. A, 200(1062), pp. 375-390, 1950.

[18] Kendoush, A.A., Theory of Convective Heat and Mass Transfer to Spherical-Cap Bubbles, AIChE Journal, 40(9), pp. 1440-1448.

[19] Clift, R., Grace, J.R. and Weber, M.E., Bubbles, Drops, and Particles, Dover Publications, Inc., Mineola, NY, 1978.

[20] Darton, R.C. and Harrison, D., The Rise of Single Gas Bubbles in Liquid Fluidised Beds, Trans. Inst. Chem. Engrs., 52, pp. 301-306, 1974.

[21] Pokorny, R. and Hrma, P., Model for the Conversion of Nuclear Waste Melter Feed to Glass, Journal of Nuclear Materials, 445, pp. 190-199, 2014. 